\title{
Facility for Removal and Determination of Labile Tritium
}

\author{
C. S. Tuta*, C. Postolache, V. Fugaru, G. Bubueanu, S. Manea, S. Bercea \\ Horia Hulubei National Institute of Physics and Nuclear Engineering, 30, Reactorului St., Magurele, Romania \\ Tritium bonded to electrophilic atoms like $\mathrm{O}, \mathrm{S}, \mathrm{N}$ or halogens can spontaneously exchange places with \\ hydrogen from the water. These tritium species are exchanged even at a very low temperature and have the \\ generic name 'labile'. In this paper, a new facility for the removal and quantitative determination of labile tritium \\ is shown. The working principle is as follows: tritium sources are brought in contact with protic solvent, leading \\ to a spontaneous exchange of labile tritium, then the obtained tritiated solvent is extracted by distillation. The \\ new facility was tested for removal efficiency of labile tritium from labeled compounds and wastes with different \\ compositions.
}

DOI: $10.12693 /$ APhysPolA.127.895

PACS: $66.30 . j p$

\section{Introduction}

Tritium (T), a heavy isotope of hydrogen, is a pure low energy $\beta$-emitter radionuclide (Transition energy $18 \mathrm{keV}$, average energy $5.7 \mathrm{keV}$ ) [1]. Its half-life is relatively small (12.26 years), which results in a high specific activity of $1073 \mathrm{TBq}(29 \mathrm{kCi}) /$ atom gram [1]. Electronic configuration and chemical properties of $\mathrm{T}$ are very similar to those of natural hydrogen $\left({ }^{1} \mathrm{H}\right.$ or protium $)$. T presents a slight difference from the point of view of physical properties and reaction speed because of atomic mass and polarizability difference.

Tritium, in its elementary form $\left(\mathrm{T}_{2} / \mathrm{HT} / \mathrm{DT}\right)$, in water (HOT/DOT) or in organic compounds with small molecular size (R-T) is easily absorbed and penetrates most of the materials.

Tritium bonded to electrophilic atoms like, O, S, N or halogens can spontaneously exchange places with hydrogen in water or in other molecules that contain $\mathrm{OH}$, $\mathrm{SH}$ or $\mathrm{NH}$ chemical groups. These tritium species are exchanged even at very low temperatures and have the generic name 'labile' [2].

The labile tritium (LT) is not recommended in labeled compounds used in the life science field. Moreover, presence of LT in radioactive wastes must be known because in this form tritium represents a high biological risk. The LT is quickly transferred into the human body through water.

In this paper, a facility for the removal and quantitative determination of LT is shown.

\section{Materials and methods}

\subsection{The labile tritium removal facility}

The working principle of the experimental facility is as follows:

*corresponding author; e-mail: catalin.tuta@nipne.ro
- Tritium sources are placed in contact with protic solvents like alcohol or water, which leads to a spontaneous exchange of LT

$$
\mathrm{R}-\mathrm{T}+\mathrm{S}-\mathrm{H} \leftrightarrow \mathrm{R}-\mathrm{H}+\mathrm{S}-\mathrm{T}
$$

- The obtained tritiated solvent is extracted by distillation, using a rotary evaporator with a highly efficient vapors retention system.

The labile tritium removal facility was created using a rotary evaporator Laborota 4000 Heidolph type, equipped with liquid nitrogen traps and vacumeter. The rotary evaporator condenser was coupled with a DLK 45 Lauda type cooler $\left(-35{ }^{\circ} \mathrm{C}\right)$ with a thermostat, Proline type, as temperature controller and recirculation system. The technological vacuum was achieved by means of a Dry Scroll SH100 Varian preliminary vacuum pump. The gaseous effluents emitted by the vacuum pump were decontaminated using a small Air Detritiation System consisting of:

- Oxidation systems of contaminant species consisting of $\mathrm{CuO}$ bed heated by means of a RT50-250/11, Naberterm electric tubular furnace.

- High efficiency retaining HTO vapors systems, resulting from the catalytic oxidation phase.

- RS 400-HTO Overhoff Tritium Gas Monitor

The facility, shown in Fig. 1, was placed into a Glove Box G SAFE T3, JACOMEX type.

\subsection{Sample preparation}

The following labeled compounds were used in the experiment: lipophilic Stable Tritium (ST) labeled compound testosterone-1,2- $\mathrm{T}_{2}$ (Tst-T) [3], hydrophilic ST labeled compound (5-Cloro-7-hidroxymethylbicyclo[2.2.1]hept-2-il)-5-fluoro-uracil-T-G (E27-5-FUT) [4] and tritiated water (HTO) with $370 \mathrm{MBq} / \mathrm{ml}$ radioactive concentration $(\mathrm{RC})$ as labile tritium source.

The Tst-T and E27-5-FU-T compounds were previously chromatographically purified and characterized in terms of radiochemical purity and radioactive concentration. The radiochemical purities were determined using liquid chromatograph Agilent 1200 series with radiochemical detectors Ramona Star, Raytest type. Ra- 


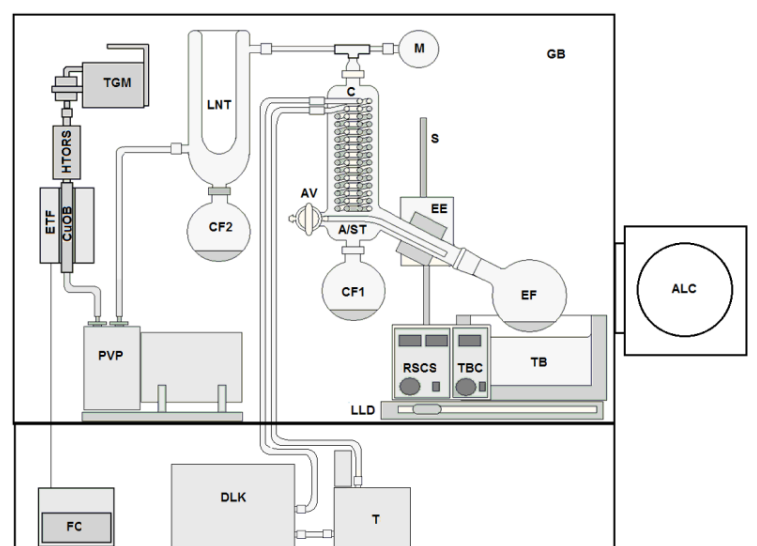

Fig. 1. The labile and volatile tritium removal facility. TB - Thermostatic bath; EF - Evaporation flask; RSC - Rotation speed controller; LLD - Lowering-lifting device; TBC - temperature bath controller, EE - Electrical engine; C - Vertical condenser; DLK - cooler; T - Thermostat; LNT - Liquid Nitrogen Trap; CF1 and CF2 Collecting flask; A /ST - Air / protic solvent inlet tube; S - Support; AV - Admission valve; M -Manometer; PVP - preliminary vacuum pump; ETF - Electric tubular furnace; FC - Furnace controller; $\mathrm{CuOB}$ - $\mathrm{CuO}$ bed; HTORS - HTO retention system; TGM - Tritium Gas Monitor; GB - Glove Box; ALC - air- lock chamber.

dioactive concentrations of liquid sources were determined using Liquid Scintillation Counter (LSC) Tricarb 2800TR PE.

The purified Tst-T, E27-5-FU-T were conditioned at $37 \mathrm{MBq} / \mathrm{ml} \mathrm{RC}$.

Samples of labeled compound solutions were prepared by mixing of Tst-T in toluene or Ent-FU-T in ethanol solutions with HTO. The volume ratios of labeled compounds to HTO were: $2 \mathrm{ml} / 0.05 \mathrm{ml}, 2 \mathrm{ml} / 0.3 \mathrm{ml}$ and $2 \mathrm{ml} / 0.6 \mathrm{ml}$ respectively.

Concrete (Portland cement, sand, clay, coarse aggregates with and without $\left.\mathrm{BaSO}_{4}\right)$ and plaster $\left(\mathrm{CaCO}_{3}\right.$ and sand) samples were crushed using a tungsten ball mill and granulometrically separated using a Sieve Shaker, WMV type. $50 \mathrm{~g}$ of powder with grain size of less than $1 \mathrm{~mm}$ was contaminated with $1 \mathrm{ml}$ Tst- $\mathrm{T}$ toluene solution $(37 \mathrm{MBq} / \mathrm{ml})$ and dried for 12 hours at $100{ }^{\circ} \mathrm{C}$ using UFE 400 oven, Memmert type. The powder was additionally contaminated with $0.1 \mathrm{ml} \mathrm{HTO}$ with $370 \mathrm{MBq} / \mathrm{ml} \mathrm{RC}$, and stored in zipper polyethylene bags.

Silicon tube and $\mathrm{Pt} / \mathrm{C} / \mathrm{PTFE}$ Isotopic Exchange Catalyst (IEC) samples with $25 \mathrm{~g}$ weight were cut in small pieces with a size of less than $1 \mathrm{~mm}$. The samples were contaminated with Tst- $\mathrm{T}$ according to the previous protocol. The LT was divided into samples using $1 \mathrm{ml}$ isopropyl alcohol $0.1 \mathrm{ml} \mathrm{HTO}$ with $370 \mathrm{MBq} / \mathrm{ml} \mathrm{RC}$. The contaminated samples were stored in zipper polyethylene bags.

Cotton wood and latex gloves samples with weight of $20 \mathrm{~g}$ were contaminated with $1 \mathrm{ml} \mathrm{E27-5-FU-T} \mathrm{ethanol}$ solution $(37 \mathrm{MBq} / \mathrm{ml} \mathrm{RC})$ and dried for 2 hours at $100{ }^{\circ} \mathrm{C}$ and after that contaminated again with $0.1 \mathrm{ml}$ HTO with $370 \mathrm{MBq} / \mathrm{ml} \mathrm{RC}$, and stored in zipper polyethylene bags.

For mineral oil samples, $50 \mathrm{ml}$ of mineral oil, $1 \mathrm{ml}$ Tst-T toluene solution $(37 \mathrm{MBq} / \mathrm{ml} \mathrm{RC})$ and $0.1 \mathrm{ml} \mathrm{HTO}(370$ $\mathrm{MBq} / \mathrm{ml} \mathrm{RC}$ ) were introduced into a $250 \mathrm{ml}$ evaporation flask (Fig. 1, EF).

For each experiment 10 sample replicates were produced.

\subsection{Determination of removal efficiency using tritium labeled compound}

The new facility was tested from the point of view of its removal yield and labeled compounds degradation. The delabilization protocol was: $40^{\circ} \mathrm{C}$ bath temperature, $20 \mathrm{ml}$ methanol as protic solvent and one evaporation step.

The removal yield $\left(\eta_{\text {delab }}\right)$ can be determined as the difference between total activities of tritium labeled compounds $\left(\Lambda_{T}\right)$ and final activities determined after delabilization steps $\left(\Lambda_{F}\right)$ divided by activities of labile tritium $\left(\Lambda_{L T}\right)$. The $\Lambda_{T}$ is equal to the sum of stable tritium compound activity $\left(\Lambda_{S T}\right)$ and $\Lambda_{L T}$. The removal yields were computed using the following equation:

$$
\begin{gathered}
\eta_{\text {delab }}[\%]=100 \cdot\left(\Lambda_{T}-\Lambda_{F}\right) / \Lambda_{L T}= \\
100 \cdot\left[\left(\Lambda_{S T}+\Lambda_{L T}\right)-\Lambda_{F}\right] / \Lambda_{L T} .
\end{gathered}
$$

Radiochemical purity of the labeled compounds after removal protocols was determined using an Agilent 1100 liquid chromatographic system.

\subsection{Determination of removal efficiency in tritium waste samples}

The LT from contaminated samples (concrete, plaster, PTFE IEC, silicon tube, glove, cotton wood and mineral oil) were determined using the new facility. The removal protocol was: methanol as protic solvent, $70{ }^{\circ} \mathrm{C}$ bath temperature, and four removing steps.

The distilled solvent activities for each sample, collected in the condenser and Liquid Nitrogen Trap flasks (Fig. 1, CF1 and CF2), were determined using previously mentioned LSC, with the obtained value representing LT.

The residual activities, representing ST, were determined by the sample's oxidation, using TRICARB Combustion Furnace 325, Packard type, and retention of resulted HTO using Tritium collector OS1700 ORTEC type.

\section{Results}

3.1. Determination of removal efficiency using tritium labeled compound

After the delabilization step, residual labeled activities slightly increase with the increasing LT activity, but the relative removal yields are practically constant for all analyzed samples. The best results were obtained in the case of Tst-T. The lesser results in E27-5-FU-T case are associated with the presence of labile positions in the molecular structure.

The final radiochemical purities decrease slightly with the increase of total activities. Here also, the best results were obtained in the case of Tst-T. The average of the obtained values, for 10 sample replicates, are shown in Table I. 
The removable yields and final radiochemical purity of labeled compounds.

TABLE I

\begin{tabular}{|c|c|c|c|c|c|c|}
\hline \multirow{2}{*}{$\begin{array}{c}\text { Labeled } \\
\text { Compound }\end{array}$} & \multicolumn{2}{|c|}{$\begin{array}{c}\text { Contaminant } \\
\text { activity }[\mathrm{MBq}]\end{array}$} & \multirow[t]{2}{*}{$\Lambda_{F}[\mathrm{MBq}]$} & \multirow[t]{2}{*}{$\eta_{\text {delab }}[\%]$} & \multirow{2}{*}{$\begin{array}{c}\text { Residual tritium } \\
\text { labeled activity }[\mathrm{MBq}]\end{array}$} & \multirow{2}{*}{$\begin{array}{c}\text { Radiochemical } \\
\text { purity [\%] }\end{array}$} \\
\hline & $\Lambda_{S T}$ & $\Lambda_{L T}$ & & & & \\
\hline Tst-T & 74.00 & 37.00 & $74.21 \pm 0.15$ & 99.43 & $0.21 \pm 0.008$ & $>97$ \\
\hline Tst-T & 74.00 & 74.00 & $74.38 \pm 0.18$ & 99.49 & $0.38 \pm 0.013$ & $>95$ \\
\hline Tst-T & 74.00 & 222.00 & $75.01 \pm 0.23$ & 99.55 & $101 \pm 0.017$ & $>94$ \\
\hline E27-5-FU-T & 74.00 & 37.00 & $74.32 \pm 0.23$ & 99.14 & $0.32 \pm 0.008$ & $>95$ \\
\hline E27-5-FU-T & 74.00 & 74.00 & $75.26 \pm 0.25$ & 98.30 & $1.26 \pm 0.017$ & $>92$ \\
\hline E27-5-FU-T & 74.00 & 222.00 & $75.87 \pm 0.26$ & 99.16 & $1.87 \pm 0.021$ & $>91$ \\
\hline
\end{tabular}

Removal process parameters, when using ethanol as extracting solvent.

TABLE II

\begin{tabular}{|c|c|c|c|c|c|c|c|}
\hline \multirow{2}{*}{$\begin{array}{l}\text { Sample } \\
\text { type }\end{array}$} & \multicolumn{2}{|c|}{$\begin{array}{l}\text { Contaminant } \\
\text { activity [MBq] }\end{array}$} & \multirow[t]{2}{*}{ Quantity } & \multirow{2}{*}{$\begin{array}{c}\text { Removed } \\
\text { activity } \\
\text { [MBq] }\end{array}$} & \multirow[t]{2}{*}{$\Lambda_{F}[\mathrm{MBq}]$} & \multirow{2}{*}{$\begin{array}{c}\text { Determined } \\
\Lambda_{T}[\mathrm{MBq}]\end{array}$} & \multirow[t]{2}{*}{$\begin{array}{l}\text { Removal } \\
\text { yield [\%] }\end{array}$} \\
\hline & $\Lambda_{S T}$ & $\Lambda_{L T}$ & & & & & \\
\hline Concrete & 37.00 & 37.00 & $50 \mathrm{~g}$ & $36.42 \pm 0.97$ & $37.62 \pm 0.57$ & $74.04 \pm 1.11$ & 98.43 \\
\hline Concrete: $\mathrm{BaSO}_{4}$ & 37.00 & 37.00 & $50 \mathrm{~g}$ & $36.59 \pm 0.89$ & $37.37 \pm 0.56$ & $73.96 \pm 1.35$ & 98.89 \\
\hline Plaster & 37.00 & 37.00 & $50 \mathrm{~g}$ & $36.58 \pm 0.70$ & $37.43 \pm 0.59$ & $74.01 \pm 1.07$ & 98.86 \\
\hline Cotton wood & 37.00 & 37.00 & $20 \mathrm{~g}$ & $36.34 \pm 0.56$ & $=0.46$ & 74.2 & 98.22 \\
\hline Latex gloves & 37.00 & 37.00 & $20 \mathrm{~g}$ & $36.82 \pm 0.46$ & $37.21 \pm 0.43$ & $74.03 \pm 0.49$ & 99.51 \\
\hline Silicon tube & 37.00 & 37.00 & $25 \mathrm{~g}$ & $36.96 \pm 0.22$ & $37.24 \pm 0.35$ & $74.2 \pm 0.46$ & 99.89 \\
\hline IEC & 37.00 & 37.00 & $25 \mathrm{~g}$ & $36.87 \pm 0.52$ & $37.25 \pm 0.51$ & $74.12 \pm 0.78$ & 99.65 \\
\hline Mineral oil & 37.00 & 37.00 & $50 \mathrm{ml}$ & $36.94 \pm 0.30$ & $37.09 \pm 0.32$ & $74.03 \pm 0.30$ & 99.84 \\
\hline
\end{tabular}

\subsection{Determination of removal efficiency in tritium waste samples}

After five removing steps, more than $98 \%$ of the LT was eliminated from each sample. The best results were obtained for the latex gloves, silicon tubes IEC and mineral oil, which is associated with quasi absence of the labile positions in the molecular structures of the components. Similarly to the case of labeled compounds, the concretes, plaster and cotton wool (with labile position in silicates, cellulose and constitutional water) show lower values of the removal yields. The mean experimental values, for 10 replicates, are shown in Table II.

\section{Conclusions}

A new facility for determination and removal of labile tritium from liquid and solid sources was created and tested. In the specific case of tritium-labeled compounds, tests have been carried out using as tritium sources, stable tritiated labeled compounds (Tst-T [3] and E27-5FU-T [4]) and HTO as labile tritium respectively. The influence of labile tritium activity effects was analyzed. The obtained results indicate a removal yield higher than $98 \%$ per step. The radiochemical purity shows a slight decrease with the increase of total activities. This increase of decomposition is due to the self-radiolytic processes associated with the increase of radioactive concentrations.

The determination of labile tritium in radioactive wastes was realized using concrete, plaster, cotton wood, latex gloves, silicon tubes, isotopic exchange catalyst and mineral oil samples contaminated with previously stable and labile tritium sources with known activities. The extraction yield was determined by measuring of removed activities at LSC and residual activities determined by catalytic oxidation, HTO trapping and activity measuring at LSC. By calculating the ratio of the experimental values to the contaminant activity values, the extraction yields were obtained. The obtained extraction yields were more than $98 \%$ when using $70{ }^{\circ} \mathrm{C}$ evaporation temperature and four extraction steps.

In all cases the removal yields were inversely proportional to the presence of labile positions in molecular structures.

\section{Acknowledgments}

This research is supported by the Project PNCDI II 177/2012 and Core Project No 09370206 from the Executive Unit for Financing Education Higher Research Development and Innovation of Romania.

\section{References}

[1] P. Davis, D. Galeriu, Environmental Radioactivity and Ecotoxicology of Radioactive Substances in: Tritium in the Environment; Encyclopedia of Sustainability Science and Technology, Ed. R.A. Meyers, Springer, New York, 2012, p. 10997.

[2] E.A. Evans, Stability of Tritium Atoms in Molecules in: Tritium and its Compounds, Butterworths, London, 1974, p. 734 .

[3] L. Matei, C. Postolache, C. Podina, J. Label. Compd. Radiopharm. 50, 442 (2007).

[4] C. Postolache, L. Matei, C. Tanase, G. Bubueanu, J. Label. Compd. Radiopharm. 53, 461 (2010). 